\title{
Randomised trial of intrapleural urokinase in the treatment of childhood empyema
}

\author{
A H Thomson, J Hull, M R Kumar, C Wallis, I M Balfour Lynn, on behalf of the British \\ Paediatric Respiratory Society Empyema Study Group
}

See end of article for authors' affiliations

.....................

Correspondence to: Dr A H Thomson, Department of Páediatrics, John Radcliffe Hospital,

Headington, Oxford OX3 9DU, UK; anne.thomson@orh.nhs.uk

Revised version received 24 September 2001

Accepted for publication

1 November 2001
Background: The role of intrapleural fibrinolytic agents in the treatment of childhood empyema has not been established. A randomised double blind placebo controlled trial of intrapleural urokinase was performed in children with parapneumonic empyema.

Methods: Sixty children (median age 3.3 years) were recruited from 10 centres and randomised to receive either intrapleural urokinase 40000 units in $40 \mathrm{ml}$ or saline 12 hourly for 3 days. The primary outcome measure was length of hospital stay after entry to the trial.

Results: Treatment with urokinase resulted in a significantly shorter hospital stay $(7.4 \vee 9.5$ days; ratio of geometric means $1.28, \mathrm{Cl} 1.16$ to $1.41 \mathrm{p}=0.027)$. A post hoc analysis showed that the use of small percutaneous drains was also associated with shorter hospital stay. Children treated with a combination of urokinase and a small drain had the shortest stay (6.0 days, $\mathrm{Cl} 4.6$ to 7.8 ).

Conclusion: Intrapleural urokinase is effective in treating empyema in children and significantly shortens hospital stay.
$\mathrm{E}$ mpyema in children usually follows an acute bacterial pneumonia and is associated with significant clinical morbidity. It has become more common in England in recent years ${ }^{1}$ but there is great heterogeneity in management reflecting the absence of good evidence on which to base treatment. The clinical problem is that of persisting fever in a child with pneumonia and a pleural collection. There is debate over the differentiation of a parapneumonic collection from an empyema and, while in reality they are probably a continuum, most authorities would accept that pus cells or bacteria in the pleural fluid or loculations on the ultrasound scan of the pleural space would merit classification as an empyema.

Conservative management of empyema with antibiotics alone or antibiotics and tube drainage often fails because the infected fluid becomes loculated and cannot be drained by a single catheter. Operative procedures such as the so-called "mini-thoracotomy" with manual attempts to break down loculations, full thoracotomy and decortication and, more recently, video assisted thoracoscopy (VATS) are all options which have been described in children. ${ }^{2}$ The use of fibrinolytic agents (streptokinase and urokinase) has recently been described in the adult literature with three small randomised controlled trials. ${ }^{4-6}$ These studies have shown increased drainage of pleural fluid and small benefits in clinical and radiographic improvement. A recent Cochrane review ${ }^{7}$ concluded that there was insufficient evidence to support routine use of intrapleural fibrinolytic therapy in the treatment of parapneumonic effusion and empyema.

There have been no controlled studies of the use of fibrinolytic agents for empyema in children, but five anecdotal and short series reports have been published..$^{8-12}$ When taken in conjunction with those in adults, these reports have led to an increase in use of fibrinolytic agents in children. The purpose of this study was to examine whether the addition of intrapleural urokinase to conventional medical management would result in a decreased duration of hospital stay in children with parapneumonic empyema.

\section{METHODS}

Patients

Previously healthy children aged 6 months to 18 years with no underlying cardiorespiratory disorder were eligible for the study if they had developed an empyema that required pleural drainage. Indications for drainage were a persistent fever of $38^{\circ} \mathrm{C}$ or greater after more than 24 hours of parenteral antibiotic treatment or the presence of a pleural collection causing respiratory distress. Patients with abnormal coagulation studies (prothrombin and partial thromboplastin times) or low platelet counts were excluded from the study.

The study was approved by a UK multicentre ethics committee (MREC) and by local ethics committees at each centre.

\section{Randomisation}

This was a double blind study. Randomisation was undertaken centrally using a blocked allocation technique in an attempt to ensure within centre randomisation. Each block consisted of six patients. All possible combinations of six numbers were generated and a random selection of 10 blocks was then selected independently. Randomisation produced a code number and centre pharmacists supplied syringes prefilled with study drug. Information was decoded only when the study was complete.

\section{Procedure}

No restriction was placed on the method of chest drain placement or the size or type of chest drain used. Patients were randomised to receive either urokinase 40000 units diluted in $40 \mathrm{ml}$ normal saline ( 10000 units diluted in $10 \mathrm{ml}$ saline if less than 1 year of age) or $40 \mathrm{ml}$ placebo (saline) given through the chest drain 12 hourly for 3 days.

After insertion of the agent the chest drain was clamped and the patient encouraged to mobilise as much as possible over the next 4 hours. Suction pressure of $-20 \mathrm{~cm} \mathrm{H}_{2} \mathrm{O}$ was then applied to the drain until the next instillation was due (8 hours later).

Measurement of oxygen saturation, respiratory rate, heart rate, $C$ reactive protein (CRP) levels, blood haemoglobin and total white blood cell (WBC) and differential counts, chest radiography and ultrasound examinations of the chest were performed at entry and on day 4. Further management was at the discretion of the managing paediatrician. 
Table 1 Organisms identified in study subjects

\begin{tabular}{lll}
\hline & Blood culture & Pleural fluid \\
\hline S pneumoniae & 4 & 3 \\
$S$ aureus & 3 & 2 \\
$S$ pyogenes & 1 \\
$S$ milleri (group) & 2 \\
$\begin{array}{l}\text { S beta haemolytic } \\
\text { (not further speciated) }\end{array}$ & 1 \\
$\begin{array}{l}\text { catarrhalis } \\
\text { Pneumococcal antigen positive }\end{array}$ & 3 & 1 \\
High ASOT & 2 & \\
\hline ASOT= Antistreptolysin O titre. & \\
\hline
\end{tabular}

Duration of hospital stay was calculated from the date of entry to the study to the date of discharge. Suggested discharge criteria were that the child should have a normal respiratory rate in air, with the temperature settled $\left(\leqslant 37.5^{\circ} \mathrm{C}\right.$ over the previous 24 hours) and with reduced or no residual pleural fluid. A follow up visit was undertaken 3 months after discharge to document recovery.

\section{Data analysis}

Pilot data were used to calculate that 25 patients were needed in each group for a power of 0.85 with $\alpha=0.05$ to demonstrate a difference in length of hospital stay of 2.5 days.

Baseline characteristics between groups were compared using Mann-Whitney U tests. The primary outcome measure was duration of hospital stay (days) after trial entry. The distribution of the data was skewed but was normal after log (base e) transformation. Comparisons between groups were carried out using two tailed Student $t$ tests. A post hoc analysis to investigate the effects of individual variables on outcome was carried out using multiple regression (backward stepwise method). ${ }^{13}$ All analyses were carried out using SPSS version 8.

\section{RESULTS}

Sixty children with a median age of 3.3 years (range 5 months to 15 years) took part in the study; 30 received urokinase and 30 received placebo. Data from two children (one in each group) were excluded before analysis because of violation of the entry criteria; both had severe spastic quadriplegia, epilepsy, and aspiration pneumonia and both required prolonged hospital care. One child (urokinase group) was withdrawn from the trial because of discomfort during the second intrapleural injection. This child's data have been included on the basis of intention to treat. Data were analysed according to the duration of hospital stay following trial entry. Children were discharged from hospital on average 0.6 days (range 0-5) after the suggested discharge criteria were met.

There were 10 treatment centres, three of which enrolled eight or more children. In 26 children the pleural fluid at initial tap was described as turbid, cloudy, or purulent and in the remainder it was described as clear or straw coloured. Of these 32 clear/straw coloured aspirates, 30 had either microscopic or ultrasonographic confirmation of empyema ( 15 contained pus cells on microscopic examination, three had a positive Gram stain, five had a positive growth on culture, and 22 had loculations on ultrasonography). Two patients had missing ultrasonographic or microscopic data but were included in the analysis. The ultrasonographic descriptions varied, and 36 of the 58 patients were noted to have either loculations $(n=23)$, septations/strands $(n=9)$, or densely echogenic collections $(\mathrm{n}=4)$. A definite causal organism was isolated in 17 patients (including the two exclusions) and a probable cause was found in a further five (table 1).

The groups were compared at trial entry. By chance, the children in the placebo group had a longer duration of illness before entry to the trial and marginally lower $\mathrm{SaO}_{2}$. There was
Table 2 Baseline characteristics of the groups (median values)

\begin{tabular}{llll}
\hline & $\begin{array}{l}\text { Urokinase } \\
(\mathrm{n}=29)\end{array}$ & $\begin{array}{l}\text { Placebo } \\
(\mathrm{n}=29)\end{array}$ & $\mathrm{p}$ Value \\
\hline Age (years) & 3.6 & 3.0 & $\mathrm{NS}$ \\
$\begin{array}{l}\text { Duration of illness (days) } \\
\mathrm{WBC}\left(10^{9} / \mathrm{l}\right)\end{array}$ & 5.0 & 9.0 & $<0.02$ \\
$\mathrm{CRP}(\mathrm{mg} / \mathrm{l})$ & 22.2 & 18.8 & $\mathrm{NS}$ \\
$\mathrm{SaO}_{2}(\%)$ & 183 & 162 & $\mathrm{NS}$ \\
$\mathrm{Pleural}^{\text {fluid }}$ & 95 & 93 & $<0.02$ \\
$\quad$ Clear & 14 & 18 & \\
$\quad$ Turbid & 15 & 11 & $\mathrm{NS}$ \\
$\begin{array}{l}\text { Ultrasonography } \\
\text { Loculated* }\end{array}$ & 21 & 19 & $\mathrm{NS}$ \\
$\quad$ Not loculated & 8 & 10 & \\
\hline
\end{tabular}

$\mathrm{WBC}=$ white blood cells; $\mathrm{CRP}=\mathrm{C}$ reactive protein; $\mathrm{SaO}_{2}=$ oxygen saturation. *Loculated includes the following descriptions: septations, strands, and densely echogenic.

no difference in age, WBC count, or CRP levels, and no significant difference in the number of children in each group with turbid or loculated pleural fluid (table 2).

Two types of drain were used (depending on the centre) which allowed two subsets of children to be identified. Small percutaneous drains of mean (SD) size 10.5 (1.7) Fr were used for 25 children ( 24 were inserted using local anaesthesia and sedation, one under general anaesthesia). Large bore drains of mean (SD) size 20.1 (4.2) Fr were used for 33 children (31 were inserted under general anaesthesia, two using local anaesthesia and sedation). There was no significant difference in age between these two subsets.

\section{Effect of urokinase on outcome}

A comparison of outcome between children treated with urokinase and those treated with placebo showed that use of urokinase during the first 4 days of the illness was associated with a significantly reduced hospital stay (7.4 days $v 9.5$ days; ratio of geometric means 1.28 , CI 1.16 to $1.41, \mathrm{p}=0.027$ ) Thus, those given placebo had, on average, a $28 \%$ longer hospital stay than the urokinase treated group. Analysis of duration of hospital stay until discharge criteria were met was similar $(6.8$ days $v 8.8$ days; ratio of geometric means 1.28 , CI 1.03 to 1.59 , $\mathrm{p}=0.03$ ). Data are presented by centre in table 3 .

\section{Effect of other factors on outcome}

When a comparison of outcome by drain type was made, the group treated using small percutaneous drains had a significantly shorter hospital stay (7.2 days $v 9.4$ days, ratio of geometric means 1.31 , CI 1.06 to $1.62, p=0.017$ ) - that is, those in whom a large drain was used had, on average, a $31 \%$ longer hospital stay than those in whom a small drain was inserted. Children treated with a combination of urokinase

Table 3 Details of length of stay and drain type used at individual centres

\begin{tabular}{lllll}
\hline Centre & $\begin{array}{l}\text { No of } \\
\text { patients }\end{array}$ & $\begin{array}{l}\text { Hospital stay in } \\
\text { days* } \\
\text { (placebo/urokinase) }\end{array}$ & $\begin{array}{l}\text { Days to discharge } \\
\text { criteria* } \\
\text { (placebo/urokinase) }\end{array}$ & $\begin{array}{l}\text { Drain type } \\
\text { (small/large) }\end{array}$ \\
\hline $\mathrm{A}$ & 1 & $-/ 9.0$ & $-/ 7.0$ & $-/ 1$ \\
$\mathrm{~B}$ & 8 & $14.2 / 11.0$ & $13.6 / 11.0$ & $0 / 8$ \\
$\mathrm{C}$ & 2 & $10.0 / 6.0$ & $9.0 / 6.0$ & $2 / 0$ \\
$\mathrm{D}$ & 20 & $8.9 / 5.4$ & $8.2 / 5.4$ & $20 / 0$ \\
$\mathrm{E}$ & 4 & $16.6 / 7.9$ & $15.8 / 6.5$ & $0 / 4$ \\
$\mathrm{~F}$ & 2 & $6.9 /-$ & $6.5 /-$ & $0 / 2$ \\
$\mathrm{G}$ & 3 & $6.3 / 18.0$ & $6.3 / 15.0$ & $3 / 0$ \\
$\mathrm{H}$ & 13 & $8.7 / 8.1$ & $8.3 / 7.7$ & $0: 13$ \\
$\mathrm{~J}$ & 2 & $6.0 / 10.0$ & $5.0 / 5.0$ & $0 / 2$ \\
$\mathrm{~L}$ & 3 & $10.5 / 5.0$ & $8.3 / 5.0$ & $0 / 3$ \\
\hline &
\end{tabular}




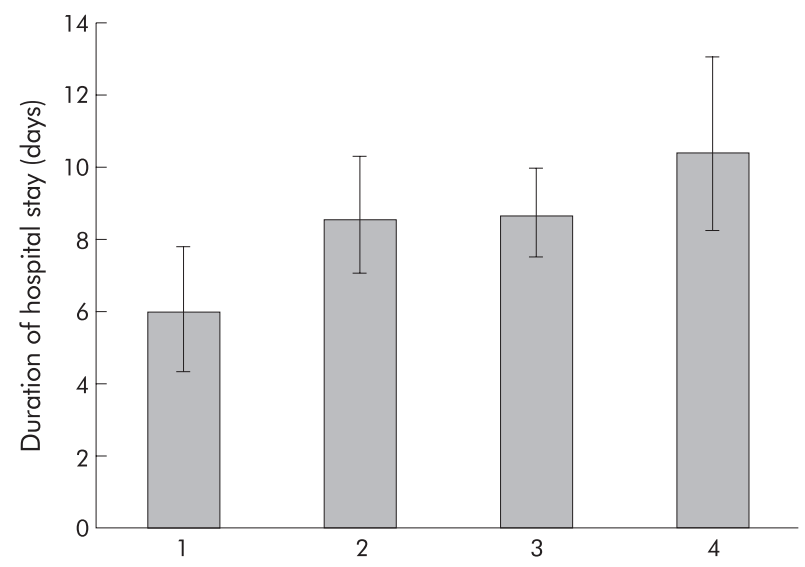

Figure 1 Graph showing duration of hospital stay after trial entry according to drain type used and drug given. Durations are geometric means with $95 \%$ confidence intervals. $1=$ urokinase and small drain ( $n=12) ; 2=$ placebo and small drain $(n=13) ; 3=u$ rokinase and large drain ( $n=17) ; 4=$ placebo and large drain ( $n=16)$.

and a small percutaneous drain had the shortest hospital stay (6.0 days, CI 4.6 to 7.8; fig 1. A Kaplan-Meier survival plot showing probability of discharge is presented in fig 2 .

Differences were found between urokinase and placebo groups at trial entry. To investigate any possible effects of these differences a post hoc analysis of factors likely to influence outcome including baseline characteristics was performed. The initial model included age, duration of illness prior to trial entry, drug given, appearance of pleural fluid, appearance of ultrasound scan, and drain type. Using a backward stepwise regression only drug given, drain type, and duration of illness remained significant in the final model (table 4). When the effects of the other factors are taken into account, the use of urokinase and a small chest drain were equally important in influencing duration of hospital stay. There was a small additional negative effect of duration of illness before trial entry such that the longer the duration of illness before entry, the shorter the length of hospital stay.

\section{Adverse events}

Four children experienced discomfort during intrapleural injection, three in the urokinase group and one in the saline group. One of the children in the urokinase group was withdrawn from the trial after the second intrapleural injection. In one child in the urokinase group the pleural fluid became blood stained after the second intrapleural injection. The treatments were continued and the blood staining resolved. No child had any disturbance of blood coagulation.

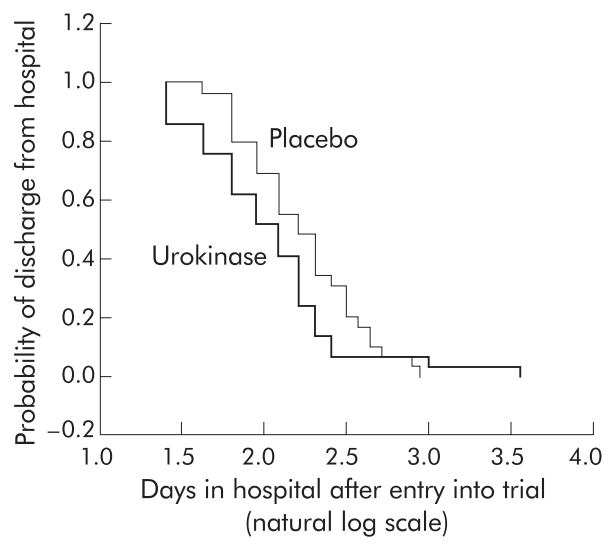

Figure 2 Kaplan-Meier survival plot showing probability of being discharged from hospital against duration of hospital stay after trial entry.
Table 4 Multiple regression using backward stepwise method

\begin{tabular}{llll}
\hline Variable & Coefficent b & Standard error & p Value \\
\hline Constant & 2.28 & 0.24 & 0.000 \\
Drug & 0.33 & 0.101 & 0.003 \\
Drain & 0.35 & 0.11 & 0.002 \\
Days unwell & -0.026 & 0.01 & 0.037 \\
\hline
\end{tabular}

Adjusted $R^{2}=0.21$. The full model included the following variables: age, days unwell, oxygen saturation $\left(\mathrm{SaO}_{2}\right), \mathrm{C}$ reactive protein (CRP), total white blood cell count (WBC), drain type, drug, pleural fluid characteristics, and ultrasound appearances. For the categorical variables drug, drain type, appearance of pleural fluid and ultrasound appearance, two categories were identified as described in the text and coded 0 and 1 for the purposes of the model.

\section{Other outcomes}

Five of the 58 children in the trial required surgical pleural decortication after day 4, three in the placebo group and two in the urokinase group. Six children (three from each group) required admission to paediatric intensive care units (mean length of stay 1.3 days). Five children (mean age 2.5 years) were given a blood transfusion, three from the urokinase group and two from the placebo group. One of 25 children treated with small drains required surgery or admission to a paediatric intensive care unit compared with five of 33 children treated with large drains.

\section{Three month follow up}

Fifty two children underwent chest radiography 3 months after discharge, 48 of which were normal or had minimal pleural thickening. Two from the placebo group had small single cysts and two from the urokinase group had minor right mid zone shadowing. Clinical examination of the chest was normal in 55 children. Three (two from the placebo group and one from the urokinase group) were reported to have quieter breath sounds on the side of the previous empyema.

\section{DISCUSSION}

This is the first randomised controlled trial of fibrinolytic agents in childhood empyema and has established clearly that the use of urokinase reduces length of hospital stay. It provides an opportunity to discuss some issues in empyema management.

Tillett and Sherry ${ }^{14}$ recommended the use of fibrinolytic agents in loculated pleural effusions as early as 1949. They proposed that such intrapleural therapy could decrease the need for surgical intervention. Since then fibrinolytic agents have been reported anecdotally in adult and, more recently, in paediatric patients. There have been three small randomised controlled trials in adults. In one there was a significantly larger volume of pleural fluid drained from the group treated with streptokinase but there were no significant differences in duration of stay, need for surgical intervention (17\%), or mortality (15\%). ${ }^{4}$ The other two studies showed that patients treated with streptokinase ${ }^{5}$ or urokinase ${ }^{6}$ drained more pleural fluid and showed clinical and radiographic improvement, but these studies were too small to examine clinical end points such as patient mortality and the frequency of surgical intervention. A large multicentre adult study organised by the British Thoracic Society is currently underway (R J Davies, personal communication). There are some differences between empyema in adults and in children. Empyema is not associated with any mortality in children in the western world and the length of hospital stay in adults is greatly influenced by co-morbid conditions. Children are generally healthy and heal rapidly. This permits the use of length of hospital stay after intervention as a primary outcome measure.

Both streptokinase and urokinase have been used extensively in adult practice and intrapleural administration does 
not cause significant activation of systemic fibrinolysis. ${ }^{15}$ Allergic reactions have been reported with the use of intrapleural streptokinase with an incidence ranging from $12.5 \%{ }^{16}$ to less than $5 \%$ ( $\mathrm{R} \mathrm{J}$ Davies, personal communication). Urokinase is of human origin and allergic reactions have not been reported. Although more expensive than streptokinase, we judged it the safer choice for use in children.

In health there is an active pleural circulation with parietal filtration and reabsorption of approximately $0.02-0.1 \mathrm{ml} / \mathrm{kg} /$ h. ${ }^{17}$ During the development of an empyema there is both increased production and decreased absorption of pleural fluid. A decrease in the normal function of fibrinolytic pathways and an increase in fibrin production results in fibrin deposition at resorption sites. ${ }^{18}$ The end point therefore in the management of empyema is not a dry pleural cavity but a re-established effective pleural circulation and a child who is afebrile. These conditions permit continued pleural healing. Fibrinolytic agents may work by decreasing fibrinous strands and reopening pleural pores blocked by fibrinous material, permitting pleural resorption.

There is conflicting evidence on the effect of fibrinolytic agents on pus viscosity. Two recent in vitro studies found that neither streptokinase nor urokinase had a significant effect in decreasing the viscosity of empyema pus. ${ }^{19}{ }^{20}$ In contrast, an in vitro study of fluid flow through percutaneous drainage catheters $^{21}$ concluded that urokinase decreased viscosity of purulent material and increased flow for all sizes of catheters.

Our study was not designed to look at the type or size of pleural drains in the management of empyema, but it was noted at analysis that the patients clearly fell into two subsets depending on normal practice at each centre. The traditional teaching is that large chest drains are required in empyema to drain pus effectively. An unexpected finding of this study was that the duration of hospital stay was shorter with small drains than with large drains. Urokinase and a small chest drain gave the best overall combined result. There are some possible explanations for this. If, as described above, the main effect of urokinase is on fibrinolysis of pleural loculations and re-establishing a pleural circulation rather than on pus viscosity, then drain size is less important. Large drains are generally inserted under general anaesthesia in children as incision through the chest wall is required. Large drains are hard and uncomfortable so that children require more analgesia and are less mobile than with small soft drains. As part of our protocol, mobility was encouraged in the 4 hour period after drug instillation into the pleural space. It is possible that pain associated with large chest drains limited patient mobility and the area of the pleural surface reached by the instilled agent was reduced, thus decreasing its effectiveness.

In order to help distinguish between a parapneumonic effusion and an empyema some authorities, particularly in the USA, determine pleural fluid glucose, $\mathrm{pH}$ or lactic dehydrogenase (LDH) levels as well as considering microscopy findings. This is not usual paediatric practice in the UK and the decision to drain a parapneumonic collection is made on clinical grounds. Nevertheless, 56 children in this study had evidence of infection in the pleural space and/or loculations in the pleural fluid. In some centres in the USA loculated pleural fluid described on ultrasonography has determined the need for thoracotomy. ${ }^{22}$ In our study ultrasonographic findings did not affect outcome and this differs from a report of image guided percutaneous drainage without the use of a fibrinolytic agent. ${ }^{23}$ Furthermore, a recent report on the role of CT scanning and ultrasound in adult patients concluded that neither technique could reliably identify the stage of pleural infection or predict those who required surgical intervention. ${ }^{24}$

Some differences were found between the groups at trial entry. The placebo group had a longer duration of illness before entry to the trial but the proportion of children with turbid pleural fluid in the placebo and urokinase groups (37\% $v 52 \%$ ) or loculated collections ( $65 \% v 72 \%$ ) was not increased. Most centres involved in the trial were tertiary respiratory centres and many children had been treated with antibiotics before transfer to the centre for further management. This may explain why, on post hoc analysis, when all other factors are taken into account, the longer the duration of illness before trial entry the shorter was the time in hospital after the intervention. There was also a marginal difference in $\mathrm{SaO}_{2}$ at trial entry but this did not influence the outcome.

The duration of hospital stay after the intervention was shorter in both groups than that reported in historical data. ${ }^{25-27}$ Despite being a multicentre randomised study, the length of stay following treatment with urokinase is comparable to that found in single centre series advocating either primary thoracotomy ${ }^{2}$ or primary VATS. ${ }^{3}$ Our study was not designed to look at cost effectiveness but urokinase costs approximately $£ 60$ per day and a small pigtail catheter is $£ 140$. This combination is likely to be considerably cheaper than any surgical intervention. Healing and remodelling are rapid in healthy children and we were not surprised to find near complete resolution of signs and radiographic appearances at 3 months, irrespective of initial severity or treatment.

This study was designed to meet the practical needs of paediatricians. The decision to tap an effusion or to place a pleural drain means a procedure under either sedation or anaesthesia. Patients were therefore not chosen for entry to the study on the basis of pleural fluid analysis but simply when a pleural collection was being drained. Similarly, our end point of length of hospital stay is simple and robust. While we accept that our suggested discharge criteria were pragmatic and open to some degree of interpretation, the median length of stay after the criteria were met was just over 12 hours. This confirms that, given current pressure on beds in tertiary centres, children do not linger in hospital after they are "better".

We conclude that intrapleural urokinase is an effective adjunct to the management of parapneumonic empyema. Duration of hospital stay is shortest when it is used in combination with a small percutaneously placed intrapleural catheter.

\section{ACKNOWLEDGEMENT}

The authors thank Dr M J F Cortina Borja, Department of Statistics, University of Oxford for his help in trial design and analysis.

\section{Authors' affiliations}

A H Thomson, J Hull, M R Kumar, John Radcliffe Hospital, Oxford, UK C Wallis, Great Ormond Street Hospital, London, UK I M Balfour Lynn, Royal Brompton and Harefield NHS Trust, London, UK

Members of the British Paediatric Respiratory Society Empyema Study Group: A Bush and M Rosenthal, Royal Brompton and Harefield NHS Trust, London; T Edmunds, Sick Children's NHS Trust Edinburgh; W Lenney, North Staffs Hospital, Stoke on Trent; S Mackenzie, Royal London Hospital, London; J Y Paton and N Gibson, Royal Hospital for Sick Children Yorkhill, Glasgow; R Primak and M Everard, Children's Hospital, Sheffield; P Seddon, Royal Alexandra Children's Hospital, Brighton; R Smyth, Royal Liverpool Children's NHS Trust, Alder Hey, Liverpool.

This study was funded by individual charitable funds at each centre and the NHS R and D levy.

Conflicts of interest: none.

\section{REFERENCES}

1 Rees JH, Spencer DA, Parikh D. et al. Increase in incidence of childhood empyema in West Midlands, UK. Lancet 1997;349:402.

2 Carey JA, Hamilton JR, Spencer DA, et al. Empyema thoracis: a role for open thoracotomy and decortication. Arch Dis Child 1998:79:510-3.

3 Kercher KW, Attorri R, Hoover JD, et al. Thoracoscopic decortication as first-line therapy for pediatric parapneumonic empyema. A case series. Chest 2000; 1 18:24-7.

4 Chin NK, Lim TK. Controlled trial of intrapleural streptokinase in the treatment of pleural empyema and complicated parapneumonic effusions. Chest 1997;111:275-9. 
5 Davies RJ, Traill ZC, Gleeson FV. Randomised controlled trial of intrapleural streptokinase in community acquired pleural infection. Thorax 1997;52:416-21.

6 Bouros D, Schiza S, Tzanakis N, et al. Intrapleural urokinase versus normal saline in the treatment of complicated parapneumonic effusions and empyema. A randomized, double- blind study. Am J Respir Crit Care Med 1999;159:37-42

7 Cameron R. Intra-pleural fibrinolytic therapy vs. conservative management in the treatment of parapneumonic effusions and empyema (Cochrane review). In: Cochrane Collaboration. Cochrane Library. Issue 3. Oxford: Update Software, 2000.

8 Rosen H, Nadkarni V, Theroux M, et al. Intrapleural streptokinase as adjunctive treatment for persistent empyema in pediatric patients. Chest 1993; 103:1190-3.

9 Stringel G, Hartman AR. Intrapleural instillation of urokinase in the treatment of loculated pleural effusions in children. J Pediatr Surg 1994;29: 1539-40.

10 Handman HP, Reuman PD. The use of urokinase for loculated thoracic empyema in children: a case report and review of the literature. Pediatr Infect Dis J 1993; 12:958-9.

11 Kornecki A, Sivan Y. Treatment of loculated pleural effusion with intrapleural urokinase in children. J Pediatr Surg 1997;32:1473-5.

12 de Benedictis FM, De Giorgi G, Niccoli A, et al. Treatment of complicated pleural effusion with intracavitary urokinase in children. Pediatr Pulmonol 2000;29:438-42.

13 Altman DG. Practical statistics for medical research. London: Chapman and Hall, 1991.

14 Tillett W, Sherry S. Effect in patients of streptococcal fibrinolysin (streptokinase) and streptococcal deoxyribonuclease on fibrinous, purulent and sanguineous exudations. J Clin Invest 1949;28:173-86.

15 Davies CW, Lok S, Davies RJ. The systemic fibrinolytic activity of intrapleural streptokinase. Am J Respir Crit Care Med 1998;157:32830 .
16 Bouros D Schiza S, Patsourakis G, et al. Intrapleural streptokinase versus urokinase in the treatment of complicated parapneumonic effusions: a prospective, double-blind study. Am J Respir Crit Care Med 1997; 155:291-5.

17 Miserocchi G. Physiology and pathophysiology of pleural fluid turnover. Eur Respir J 1997:10:219-25.

18 Kroegel C, Antony VB. Immunobiology of pleural inflammation: potential implications for pathogenesis, diagnosis and therapy. Eur Respir J 1997; 10:2411-8.

19 Light RW, Nguyen T, Mulligan ME, et al. The in vitro efficacy of varidase versus streptokinase or urokinase for liquefying thick purulent exudative material from loculated empyema. Lung 2000;178:13-8.

20 Simpson G, Roomes D, Heron M. Effects of streptokinase and deoxyribonuclease on viscosity of human surgical and empyema pus. Chest 2000;1 17: 1728-33.

21 Park JK, Kraus FC, Haaga JR. Fluid flow during percutaneous drainage procedures: an in vitro study of the effects of fluid viscosity, catheter size, and adjunctive urokinase. AJR Am J Roentgenol 1993;160:165-9.

22 Shankar KR, Kenny SE, Okoye BO, et al. Evolving experience in the management of empyema thoracis. Acta Paediatr 2000;89:417-20.

23 Shankar S, Gulati M, Kang M, et al. Image-guided percutaneous drainage of thoracic empyema: can sonography predict the outcome? Eur Radiol 2000; 10:495-9.

24 Kearney SE, Davies CW, Davies R, et al. Computed tomography and ultrasound in parapneumonic effusions and empyema. Clin Radiol 2000;55:542-7.

25 Chan W, Keyser-Gauvin E, Davis GM, et al. Empyema thoracis in children: a 26-year review of the Montreal Children's Hospital experience. J Pediatr Surg 1997;32:870-2.

26 Freii BJ, Kusmiesz H, Nelson JD, et al. Parapneumonic effusions and empyema in hospitalized children: a retrospective review of 227 cases. Pediatr Infect Dis 1984;3:578-91.

27 Chan PW, Crawford O, Wallis C, et al. Treatment of pleural empyema. J Paediatr Child Health 2000;36:375-7. 